\title{
Effects of Orography and Surface Heat Fluxes on the South Asian Summer Monsoon
}

\section{Citation}

Ma, Ding, William Boos, and Zhiming Kuang. 2014. "Effects of Orography and Surface Heat Fluxes on the South Asian Summer Monsoon." Journal of Climate 27 (17) (September): 66476659. doi:10.1175/jcli-d-14-00138.1.

\section{Published Version}

10.1175/jcli-d-14-00138.1

\section{Permanent link}

http://nrs.harvard.edu/urn-3:HUL.InstRepos:34353266

\section{Terms of Use}

This article was downloaded from Harvard University's DASH repository, and is made available under the terms and conditions applicable to Other Posted Material, as set forth at http:// nrs.harvard.edu/urn-3:HUL.InstRepos:dash.current.terms-of-use\#LAA

\section{Share Your Story}

The Harvard community has made this article openly available.

Please share how this access benefits you. Submit a story.

\section{Accessibility}




\title{
Effects of Orography and Surface Heat Fluxes on the South Asian Summer Monsoon
}

\author{
DING MA \\ Department of Earth and Planetary Sciences, Harvard University, Cambridge, Massachusetts \\ WILLIAM BoOS \\ Department of Geology and Geophysics, Yale University, New Haven, Connecticut \\ ZHIMING KUANG \\ Department of Earth and Planetary Sciences, and School of Engineering and Applied Sciences, Harvard University, Cambridge, \\ Massachusetts
}

(Manuscript received 21 February 2014, in final form 16 May 2014)

\begin{abstract}
A high-resolution ( $40 \mathrm{~km}$ horizontal) global model is used to examine controls on the South Asian summer monsoon by orography and surface heat fluxes. In a series of integrations with altered topography and reduced surface heat fluxes, monsoon strength, as indicated by a vertical wind shear index, is highly correlated with the amplitude of the maximum boundary layer equivalent potential temperature $\left(\theta_{\mathrm{eb}}\right)$ over South Asia. Removal of the Tibetan Plateau while preserving the Himalayas and adjacent mountain ranges has little effect on monsoon strength, and monsoon strength decreases approximately linearly as the height of the Himalayas is reduced. In terms of surface heat flux changes, monsoon strength is most sensitive to those in the location of the $\theta_{\mathrm{eb}}$ maximum just south of the Himalayas. These results are consistent with the recent idea that topography creates a strong monsoon by insulating the thermal maximum from dry extratropical air. However, monsoon strength is found to be more sensitive to variations in the $\theta_{\mathrm{eb}}$ maximum when topography is altered than when surface heat fluxes are reduced, and it is suggested that free-tropospheric humidity changes lead to deviations from strict convective quasi equilibrium and cause this difference. When topography is reduced, dry extratropical air intrudes into the troposphere over the $\theta_{\mathrm{eb}}$ maximum and is entrained by local deep convection, requiring a higher $\theta_{\mathrm{eb}}$ to achieve convective equilibrium with a given upper-tropospheric temperature and associated balanced monsoon flow. These results illustrate potential complexities that need to be included in simple theories for monsoon strength built on strict convective quasi equilibrium.
\end{abstract}

\section{Introduction}

The boreal summer South Asian monsoon is a major feature of the general circulation of the Earth's atmosphere and affects the lives of billions of people (e.g., Lau et al. 2006). The thermally direct monsoon circulation is caused by the thermodynamic contrast between the Eurasian continent and the Indian Ocean. In particular, the Tibetan Plateau has for decades been thought to drive this large-scale monsoon by acting as an elevated heat source (Yeh et al. 1957). The sensible heat flux from the surface of the Tibetan Plateau in spring was argued to heat air

Corresponding author address: Ding Ma, Harvard University, 20 Oxford St., Cambridge, MA 02138.

E-mail: dingma@fas.harvard.edu above the plateau to higher temperatures than air over surrounding nonelevated surfaces, leading to the reversal of the free-tropospheric meridional temperature gradient that accompanies the onset of the monsoon. The meridional temperature gradient would then be maintained through the summer by a combination of surface heat fluxes, the diabatic heating of precipitating convection that is caused by the plateau-induced ascent, and adiabatic warming by dynamically induced subsidence (e.g., He et al. 1987; Yanai et al. 1992; Wu and Zhang 1998). The importance of elevated heating seemed to be supported by the fact that the intensity and northward extent of monsoon precipitation were greatly reduced in model simulations in which all topography was removed (e.g., Hahn and Manabe 1975; Prell and Kutzbach 1992). Temporal correlations between Tibetan Plateau uplift 
and some proxy indicators of monsoon strength seem to support the idea that elevated topography creates a strong monsoon (e.g., An et al. 2001), but there is considerable uncertainty in the timing of orographic uplift and in the interpretation of proxies for monsoon strength (see review by Molnar et al. 2010).

While Asian topography is clearly needed to produce a strong monsoon circulation, the roles of the broad Tibetan Plateau and the comparatively narrow mountain ranges adjacent to the plateau (e.g., the Himalayas) were not distinguished in many previous modeling studies (e.g., Abe et al. 2003; Yasunari et al. 2006). As reproduced in Fig. 1a, modern observations (e.g., Boos and Emanuel 2009) show that the maximum free-tropospheric temperature is centered slightly south of the peaks of the Himalayas (the thick white curve in Fig. 1a) instead of being centered over or to the northwest of the Tibetan Plateau as one would expect for the response to a heat source (e.g., Gill 1980). The free-tropospheric temperature maximum lies almost directly over the maximum boundary layer equivalent potential temperature $\left(\theta_{\mathrm{eb}}\right.$; Fig. 1b), consistent with convective quasi-equilibrium treatments of precipitating large-scale flow as discussed in Boos and Emanuel (2009), and the maximum $\theta_{\mathrm{eb}}$ is located over the nonelevated region of northern India. These facts, together with the existence of sharp horizontal gradients in $\theta_{\mathrm{eb}}$ coincident with the Himalayas and adjacent mountain ranges, led Boos and Kuang (2010) to hypothesize that topography creates a strong monsoon primarily by insulating the monsoon thermal maximum from the low $\theta_{\mathrm{eb}}$ (i.e., dry) air of the Asian continental interior (see also Chakraborty et al. 2006). They confirmed that the monsoon circulation is largely unchanged by removal of the Tibetan Plateau in a climate model as long as the Himalayas and adjacent mountain ranges are preserved. These model results and observations of $\theta_{\mathrm{eb}}$ are consistent with the idea that the elevated heating over the Tibetan Plateau is not crucial to the monsoon, but the radiative and surface heat fluxes over the nonelevated parts of northern India are important. Wu et al. (2012) subsequently argued that the surface sensible heat flux from the southern slopes of the Himalayas provides an elevated heating that drives a large part of the monsoon and showed that monsoon strength decreased when sensible heating from these mountain ranges was suppressed in a climate model. However, additional model simulations showed that the monsoon is more sensitive to heat fluxes from nonelevated surfaces over northern India than it is to heat fluxes from the Himalayas and other elevated terrain (Boos and Kuang 2013). Thus, surface heat fluxes in the region of the $\theta_{\mathrm{eb}}$ maximum seem to be most important for monsoon strength, with topography creating a strong monsoon primarily by suppressing the horizontal advective flux of low equivalent potential temperature $\left(\theta_{e}\right)$ air into the thermal maximum.

However, all of the studies discussed above used models with coarse resolution that barely resolve topographic details in the regions of interest. For example, the narrow range of the Himalayas is not distinct from the Tibetan Plateau in a climate model integrated at $2^{\circ}$ horizontal resolution. Cane (2010) noted the need for results concerning the role of topography in the South Asian summer monsoon to be reproduced in higherresolution models. Boos and Hurley (2013) found that a collection of the latest generation of climate models has a negative bias in the strength of the monsoon thermal maximum that seems to be caused by an overly strong flow of dry air across the smoothed model topography. With these motivations, here we employ the Weather Research and Forecast (WRF) Model as a high-resolution general circulation model to explore the effects of orography and surface heat fluxes on the South Asian summer monsoon. This model is integrated at 40-km horizontal resolution, substantially finer than the roughly $200-\mathrm{km}$ resolution employed by Boos and Kuang (2010) or the wavenumber 42 rhomboidal truncation used in the spectral model of Wu et al. (2012). Furthermore, we conducted a fairly large number of model experiments in which topographic heights and surface heat fluxes were altered. The results provide insight into the relative importance of topography and regional surface heat fluxes in setting the monsoon strength.

\section{Model and methods}

Using WRF version 3, 11 sets of global experiments were conducted. All integrations were performed with the horizontal resolution of $40 \mathrm{~km}$ and 40 vertical levels with prescribed sea surface temperature and sea ice. Convection is explicitly represented in the model using the reduced acceleration in the vertical (RAVE) methodology of Kuang et al. (2005), with a RAVE factor of 10. This method rescales convective motions and largescale circulations and allows global integrations at coarser resolutions with explicit (rather than parameterized) convection. The Noah land surface model was used over land. When the topography was modified, only the surface elevations were changed, and all other fixed properties of the land, such as soil temperature at the lower boundary of the land surface model, were left unchanged. A sensible heat sink was prescribed in the land surface scheme in the experiments with reduced surface sensible heat fluxes. All runs were started in late February or early March using initial conditions from 

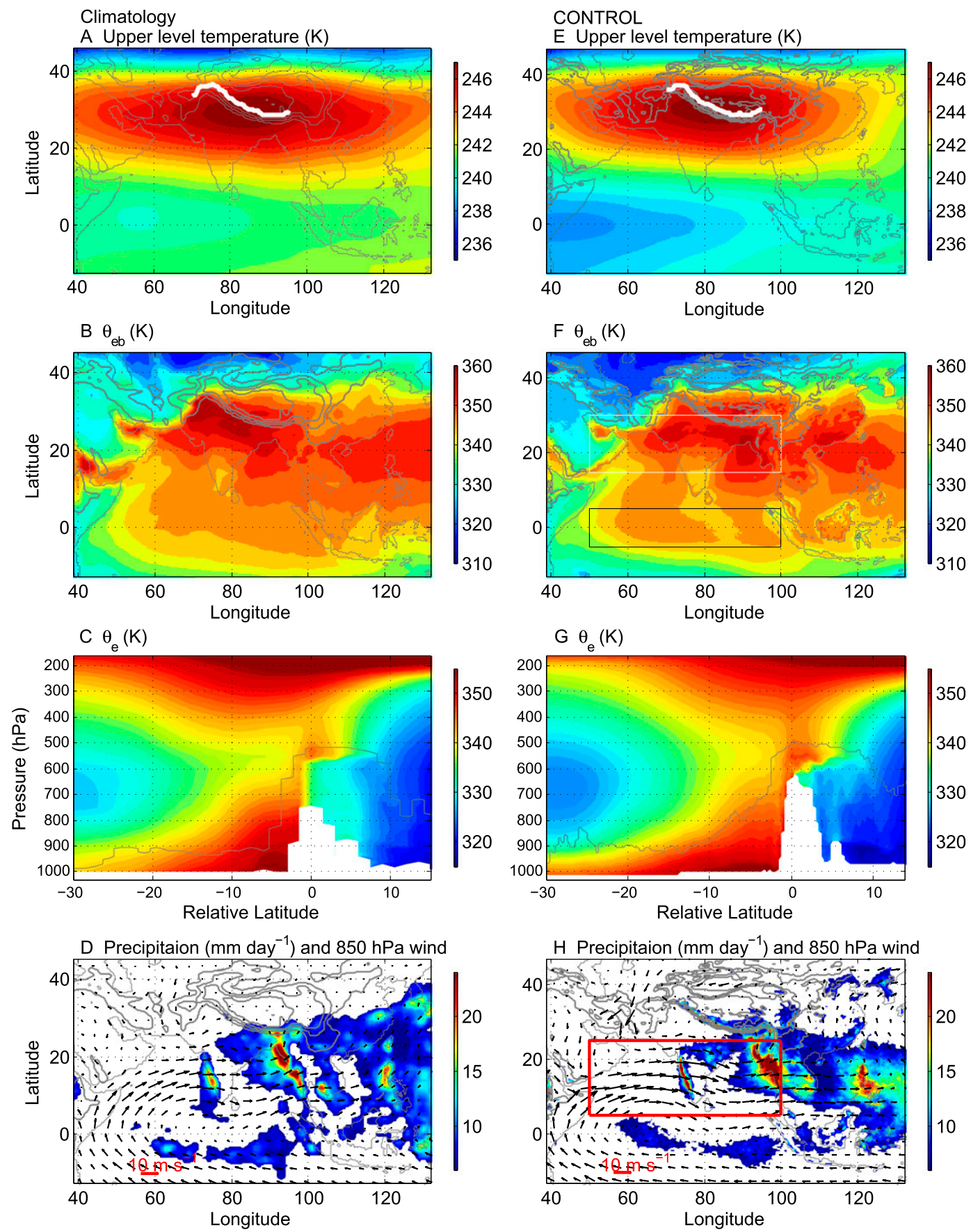

FIG. 1. The thermodynamic structure, precipitation, and wind from observations, reanalysis data, and the CONTROL. (a) ERA-40 temperature averaged between 175 and $450 \mathrm{hPa}$. (b) ERA- $40 \theta_{\mathrm{eb}}: \theta_{e}$ about $20 \mathrm{hPa}$ above the surface. (c) Vertical-meridional distributions of the $\theta_{e}$ from the ERA- 40 averaged between $70^{\circ}$ and $95^{\circ} \mathrm{E}$ along the lines at the same relative latitude with respect to the peaks of the Himalayas [indicated by the thick white curve in (a)]. (d) TRMM precipitation rate (color shading) and ERA-40 850-hPa winds (vectors). (e)-(h) The corresponding properties of averages of ensemble members from the CONTROL experiment. In (f), the white box denotes the domain in which regions covering $3.7 \times 10^{6} \mathrm{~km}^{2}$ of the highest $\theta_{\mathrm{eb}}$ are identified to calculate the maximum $\theta_{\mathrm{eb}}$ over northern India. The black box indicates the domain in the equatorial Indian Ocean where the reference $\theta_{e}^{*}$ is averaged

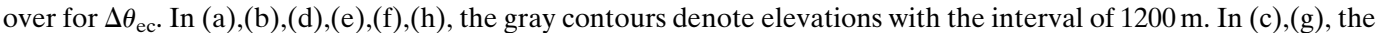
gray curve shows the maximum height of the orography along the relative latitude, so that, below the gray curve, along each relative latitude there are different numbers of invalid data points that are not considered into the average. In (h), the red box defines the region to calculate the mWYI. 
TABLE 1. Experiments configuration: The elevations of the altered orography in HIM90, HIM66, HIM33, and FLAT are denoted by the thin gray contours in Figs. 2a-d with an interval of $1200 \mathrm{~m}$. A sensible heat sink of $150 \mathrm{~W} \mathrm{~m}^{-2}$ is prescribed in the land surface scheme in the first group of experiments with reduced surface sensible heat fluxes. In the second group of experiments with reduced surface sensible heat fluxes, the magnitude of surface sensible heat fluxes forcing follows the distribution of differences between $\theta_{\mathrm{eb}}$ values for the FLAT experiment and those for the CONTROL experiment. TIBET includes the part of the Tibetan Plateau north of the Himalayas as denoted by the thick black contour in Fig. 2e. HIM (thick black contour in Fig. 2f) is defined as the region above $1200 \mathrm{~m}$ on the southern slope of the Himalayas, $70^{\circ}-100^{\circ} \mathrm{E}$, and covers $7.6 \times 10^{5} \mathrm{~km}^{2}$. INDIA (thick black contour in Fig. $2 \mathrm{~g}$ ) covers the same areal extent as HIM and is directly south of and adjacent to the HIM. INDIA2 (thick black contour in Fig. $2 \mathrm{~h}$ ) is defined as the region with the highest $\theta_{\mathrm{eb}}$ in the CONTROL covering $7.6 \times 10^{5} \mathrm{~km}^{2}$. THERM (thick black contour in Fig. $6 \mathrm{a}$ ) is the region south of the Himalayas, north to $22.5^{\circ} \mathrm{N}, 67^{\circ}-90^{\circ} \mathrm{E}$.

\begin{tabular}{|c|c|c|}
\hline & Variation in input & Note \\
\hline CONTROL & - & \\
\hline HIM90 & $\begin{array}{l}\text { Tibetan Plateau removed; } 90 \% \\
\text { of Himalayas preserved }\end{array}$ & Fig. $2 \mathrm{a}$ \\
\hline HIM66 & $\begin{array}{l}\text { Tibetan Plateau removed; } 66 \% \text { of } \\
\text { Himalayas preserved }\end{array}$ & Fig. $2 b$ \\
\hline HIM33 & $\begin{array}{l}\text { Tibetan Plateau removed; } 33 \% \text { of } \\
\text { Himalayas preserved }\end{array}$ & Fig. 2c \\
\hline FLAT & $\begin{array}{l}\text { elevation set to } 0 \text { north to } 20^{\circ} \mathrm{N} \text {, } \\
60^{\circ}-120^{\circ} \mathrm{E}\end{array}$ & Fig. 2d \\
\hline TIBET & $\begin{array}{l}344 \text { TW of sensible heat sink in TIBET } \\
\text { (over the Tibetan Plateau) }\end{array}$ & Fig. $2 \mathrm{e}$ \\
\hline HIM & $\begin{array}{l}114 \mathrm{TW} \text { of sensible heat sink in HIM } \\
\text { (over southern slope of the Himalayas) }\end{array}$ & Fig. $2 f$ \\
\hline INDIA & $\begin{array}{l}114 \text { TW of sensible heat sink in INDIA } \\
\text { (over northern India) }\end{array}$ & Fig. $2 g$ \\
\hline INDIA2 & $\begin{array}{l}114 \mathrm{TW} \text { of sensible heat sink in INDIA2 } \\
\text { (over northern India) }\end{array}$ & Fig. $2 \mathrm{~h}$ \\
\hline THERM1 & $\begin{array}{l}196 \text { TW of sensible heat sink in } \\
\text { THERM (over northern India) }\end{array}$ & Fig. 6a \\
\hline THERM2 & $\begin{array}{l}392 \text { TW of sensible heat sink in } \\
\text { THERM (over northern India) }\end{array}$ & Fig. $6 a$ \\
\hline THERM3 & $\begin{array}{l}588 \text { TW of sensible heat sink in } \\
\text { THERM (over northern India) }\end{array}$ & Fig. $6 \mathrm{a}$ \\
\hline
\end{tabular}

the National Centers for Environmental Prediction reanalysis data, and time averages were taken and analyzed in June, July, and August.

Table 1 provides a brief summary of the experiments design. With no modification of the surface heat fluxes, the standard WRF topography (the thin gray contours in Fig. 1e) is used in the control simulations, referred to as CONTROL. The orography is modified in HIM90, HIM66, HIM33 and FLAT, and each experiment with altered orography consists of an ensemble of three simulations, integrated globally from 27 February, 1 March, and 3 March to 1 September 1999. For HIM90, the surface elevations are first set to zero north of the point at which the Himalayas reach $90 \%$ of the elevation of the highest point at each longitude between $70^{\circ}$ and $100^{\circ} \mathrm{E}$, so that the bulk of the Tibetan Plateau is removed while the narrow range of the Himalayas is mostly preserved. Then a poleward slope of $10 \mathrm{~m} \mathrm{~km}^{-1}$ is applied north of the point with the highest elevation to avoid numerical instability. The thin gray contours in Fig. 2a denote the topography implemented in HIM90. We did not keep $100 \%$ of the maximum height at each longitude because the highest point is located north of the Himalayas at some longitudes. HIM66 and HIM33 are configured similarly as in HIM90, except that the Himalayas are truncated at $66 \%$ and $33 \%$ of the maximum height at each longitude, respectively. The topography for these two experiments is illustrated in Figs. 2b,c. In FLAT, the elevations are set to zero north of $20^{\circ} \mathrm{N}$ and between $60^{\circ}$ and $120^{\circ} \mathrm{E}$, as shown in Fig. $2 \mathrm{~d}$ ).

After the surface fluxes are calculated in the land surface scheme at each time step, a sensible heat sink of $150 \mathrm{~W} \mathrm{~m}^{-2}$ is applied to the bottom layer of the atmosphere over a series of target regions in the first group of experiments with reduced surface heat fluxes (i.e., TIBET, HIM, INDIA, and INDIA2). To improve the signal-tonoise ratio, the CONTROL, TIBET, HIM, INDIA, and INDIA2 experiments include 10 integrations, each starting from an individual date from 24 February through 5 March 1999. TIBET covers the regions with elevations higher than $1200 \mathrm{~m}$ north of the Himalayas between $70^{\circ}$ and $100^{\circ} \mathrm{E}$ (denoted by the thick black contour in Fig. $2 \mathrm{e}$ ), and the total reduction of surface sensible heat flux is $344 \mathrm{TW}$ in the TIBET experiment. HIM is defined as the region above $1200 \mathrm{~m}$ on the southern slope of the Himalayas, between $70^{\circ}$ and $100^{\circ} \mathrm{E}$, and covers around $7.6 \times 10^{5} \mathrm{~km}^{2}$ (thick black contour in Fig. 2f). INDIA is the region covering the area of $7.6 \times 10^{5} \mathrm{~km}^{2}$, the same as HIM, and is south of and adjacent to HIM (thick black contour in Fig. 2g). INDIA2 (thick black contour in Fig. 2h) also covers $7.6 \times 10^{5} \mathrm{~km}^{2}$, but it consists of the regions with the highest $\theta_{\mathrm{eb}}$ in the CONTROL. The total forcing of surface sensible heat fluxes in HIM, INDIA, and INDIA2 is $114 \mathrm{TW}$. We also conduct a second group of experiments with modified surface sensible heat fluxes. In THERM1, the amplitude of the surface heat flux forcing follows the distribution of differences between $\theta_{\mathrm{eb}}$ values for the FLAT experiment and those for the CONTROL experiment, and the sensible heat flux is reduced over the region north of $22.5^{\circ} \mathrm{N}$ and south of the Himalayas between $67^{\circ}$ and $92^{\circ} \mathrm{E}$ (thick black contour in Fig. 6a, described in more detail below). In total, $196 \mathrm{TW}$ of surface sensible heat fluxes is eliminated in THERM1. Then, in THERM2 and THERM3, the remaining surface sensible heat flux forcing is doubled and tripled, respectively. For THERM1, THERM2, and THERM3, the second group of experiments with reduced surface heat fluxes, four integrations are conducted in 

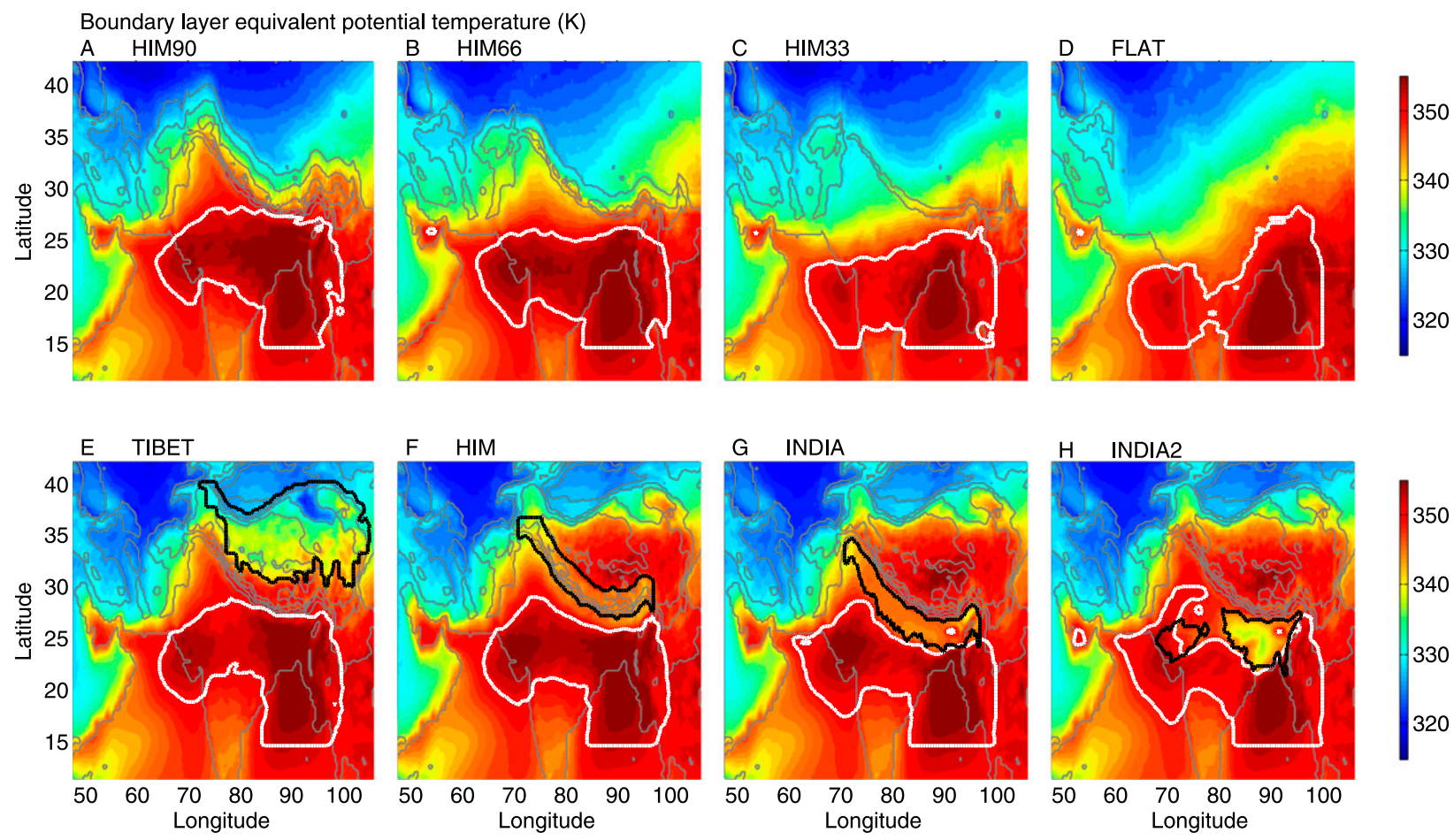

FIG. 2. The spatial distribution of $\theta_{\mathrm{eb}}$ averaged for June, July, and August (color shading). The thick white contours denote the regions covering $3.7 \times 10^{6} \mathrm{~km}^{2}$ of the highest $\theta_{\mathrm{eb}}$ within $50^{\circ}-100^{\circ} \mathrm{E}, 15^{\circ}-30^{\circ} \mathrm{N}$. The thin gray contours denote elevations with the interval of $1200 \mathrm{~m}$. (bottom) The thick black contours show the regions where a sensible heat sink is applied on the surface.

each experiment starting from 27 February, 1 March, 2 March, and 3 March.

The strength of the monsoon is quantified using an index based on the spatially averaged vertical wind shear (Webster and Yang 1992). To better represent the dominant mode of interannual variations of the South Asian summer monsoon, instead of using the original definition of the Webster-Yang index, we followed Wang et al. (2001) and used the modified Webster-Yang index ( $\mathrm{mWYI}$ ). This $\mathrm{mWYI}$ is defined as the difference in zonal wind between 200 and $850 \mathrm{hPa}$, averaged from $5^{\circ}$ to $25^{\circ} \mathrm{N}$ and from $50^{\circ}$ to $100^{\circ} \mathrm{E}$ (indicated by the red box in Fig. 1h). We also tried the Somali jet index defined by Boos and Emanuel (2009) to indicate the strength of the monsoon: the fact that the Somali jet index produced similar results as those from the mWYI suggests that our results are not highly sensitive to the choice of index.

\section{Results and discussion}

With realistic topography, the CONTROL runs produce similar precipitation to that estimated from the Tropical Rainfall Measuring Mission (TRMM) 3B43V6 data averaged for June, July, and August 1999 (Figs. 1d,h). The precipitation maxima are located off the Western Ghats in India, over the southern slope of the Himalayas and the coastal mountains of Myanmar. The precipitation peaks at around $24 \mathrm{~mm} \mathrm{day}^{-1}$, similar to the observations. The simulated $850-\mathrm{hPa}$ winds capture the main pattern of the large-scale circulation represented in 40-yr European Centre for Medium-Range Weather Forecasts Re-Analysis (ERA-40) data averaged for the same period. There is strong westerly flow over the north Indian Ocean and the Indian subcontinent. The modeled $\theta_{\mathrm{eb}}$ (Fig. 1f) and upper-tropospheric temperature (Fig. 1e) generally agree with the ERA-40 data (Figs. 1a,b), with the $\theta_{\mathrm{eb}}$ maximum positioned in north India and the center of maximum upper-tropospheric temperature located slightly south of the peaks of the narrow range of mountains (the thick white curve in Fig. 1e). Although the model results show some bias compared to the observationally based estimates, such as overly strong lowlevel westerlies and a $\theta_{\mathrm{eb}}$ maximum that is slightly weaker and positioned too far south, the climatology produced by the WRF Model is substantially better than that produced by almost all global climate models previously used to study the boreal summer South Asian monsoon (e.g., Boos and Kuang 2010; Wu et al. 2012; Boos and Hurley 2013).

The vertical cross section of the $\theta_{e}$ profile from the CONTROL experiment (Fig. 1g), averaged between $70^{\circ}$ and $95^{\circ} \mathrm{E}$ in relative distance to the peaks of the Himalayas 


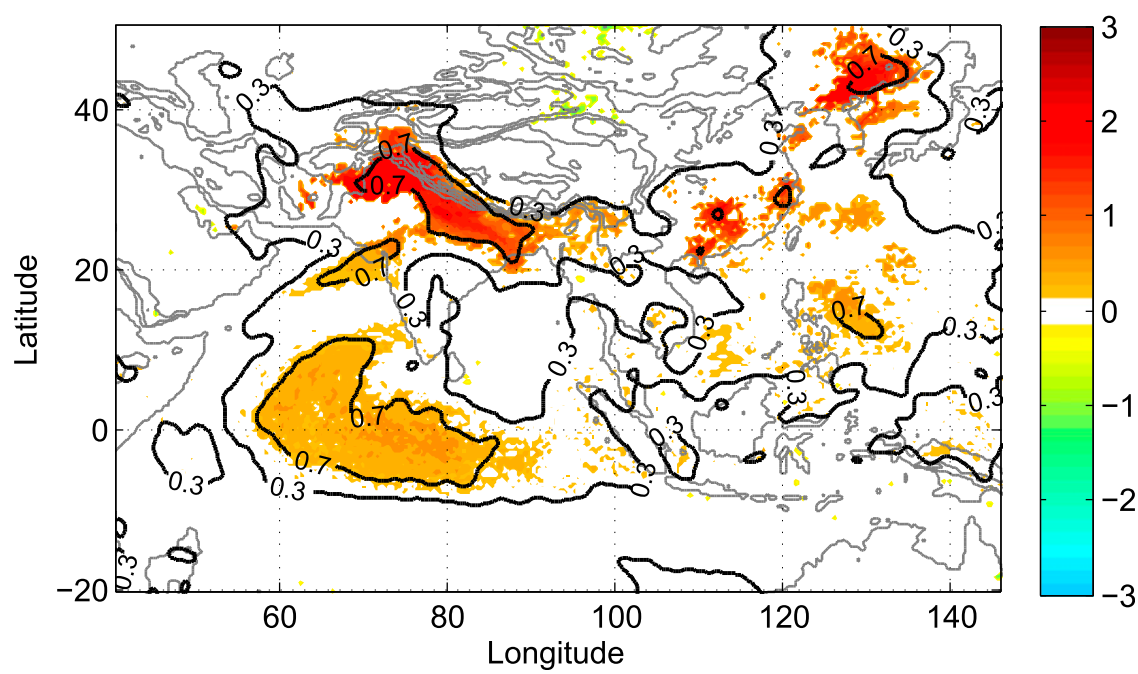

FIG. 3. Spatial distribution of the regression coefficient between the $\theta_{\mathrm{eb}}$ and the mWYI from the CONTROL. Color shading represents the regression coefficients $\left(\mathrm{K} \mathrm{m}^{-1} \mathrm{~s}\right)$ that are statistically significant at $95 \%$ confidence level. The thick black contours indicate regions with correlation coefficients of 0.3 and 0.7 . The thin gray contours denote elevations with interval of $1200 \mathrm{~m}$.

at that longitude, is also consistent, in spite of different resolutions, with that derived from the ERA-40 data (Fig. 1c). The gray curves in Figs. 1c,g define the maximum elevation along each relative latitude, with $0^{\circ}$ in relative latitude representing the location of the Himalayan peaks (the thick white curves in Figs. 1a,e). The sharp gradient in $\theta_{\mathrm{eb}}$ is consistent with the hypothesis that the Himalayas insulate the $\theta_{\mathrm{eb}}$ maximum against the low $\theta_{e}$ air in the north. A rough scale for the anomalous horizontal moist static energy flux divergence in the experiments where the topography is eliminated can be estimated by $\langle v(\partial h / \partial y)\rangle$, where $v, h$, and $y$ are the anomalous meridional velocity, the basic state moist static energy, and the meridional distance, respectively, and angle brackets denote a mass-weighted vertical integral. An estimate of the moist static energy gradient can be obtained from the $\theta_{e}$ field using $(\partial h / \partial y) \approx\left(c_{\mathrm{pd}} T / \theta_{e}\right)\left(\partial \theta_{e} / \partial y\right)$, in which $c_{\mathrm{pd}}$ is the heat capacity for dry air and $T$ is the temperature. Assuming the scale for $v$ is $1 \mathrm{~m} \mathrm{~s}^{-1}$ and using a rough scale for $\partial \theta_{e} / \partial y$ from the observations, the anomalous horizontal moist static energy flux divergence is around $150 \mathrm{~W} \mathrm{~m}^{-2}$. The scale for the anomalous moist static energy flux divergence in the experiments with altered orography is comparable with the imposed surface heat flux forcing in the experiments with reduced sensible heat fluxes, so we expect the response of the monsoon to share the same order of magnitude in the experiments with altered orography and reduced sensible heat fluxes.

The 10 integrations in CONTROL yield an average $\mathrm{mWYI}$ of $35.7 \pm 0.28 \mathrm{~m} \mathrm{~s}^{-1}$, with the error of the mean estimated assuming a Gaussian distribution of error. Using 3-month means for June, July, and August, we regress the mWYI on $\theta_{\mathrm{eb}}$ at each horizontal location for the 10 integrations of the CONTROL experiment, which are analogs for 10 different monsoon seasons. As shown in Fig. 3, the mWYI is most strongly correlated with $\theta_{\mathrm{eb}}$ in north India, very near the $\theta_{\mathrm{eb}}$ maximum. The regression coefficients indicate the pattern of $\theta_{\mathrm{eb}}$ anomaly in a year with strong monsoon circulation, and the contrast of regression coefficients between north India and the equatorial Indian Ocean shows that a stronger monsoon circulation is accompanied by a stronger meridional $\theta_{\mathrm{eb}}$ gradient. The positive correlation over the Indian Ocean does not result from any local changes in sea surface temperature because sea surface temperature does not vary between the runs, so we conclude that it results from increased $\theta_{\mathrm{eb}}$ because of intensified circulation. The positive signal in the East Asian marginal seas agrees with the results from the composite analysis by Wang et al. (2001) and was attributed to teleconnections with the surface warming associated with an anomalous anticyclone. The regression pattern for our model is similar to that calculated from 45 years of interannual variations in observed monsoon precipitation and $\theta_{\mathrm{eb}}$ (Hurley and Boos 2013, their Fig. 2b).

When all orography is removed within $60^{\circ}-120^{\circ} \mathrm{E}$, $20^{\circ}-90^{\circ} \mathrm{N}$ in the FLAT experiment, the monsoon circulation weakens greatly as in previous studies (e.g., Chakraborty et al. 2002), and the mWYI drops to around $23 \mathrm{~m} \mathrm{~s}^{-1}$ (Fig. 4a). Precipitation over north India 

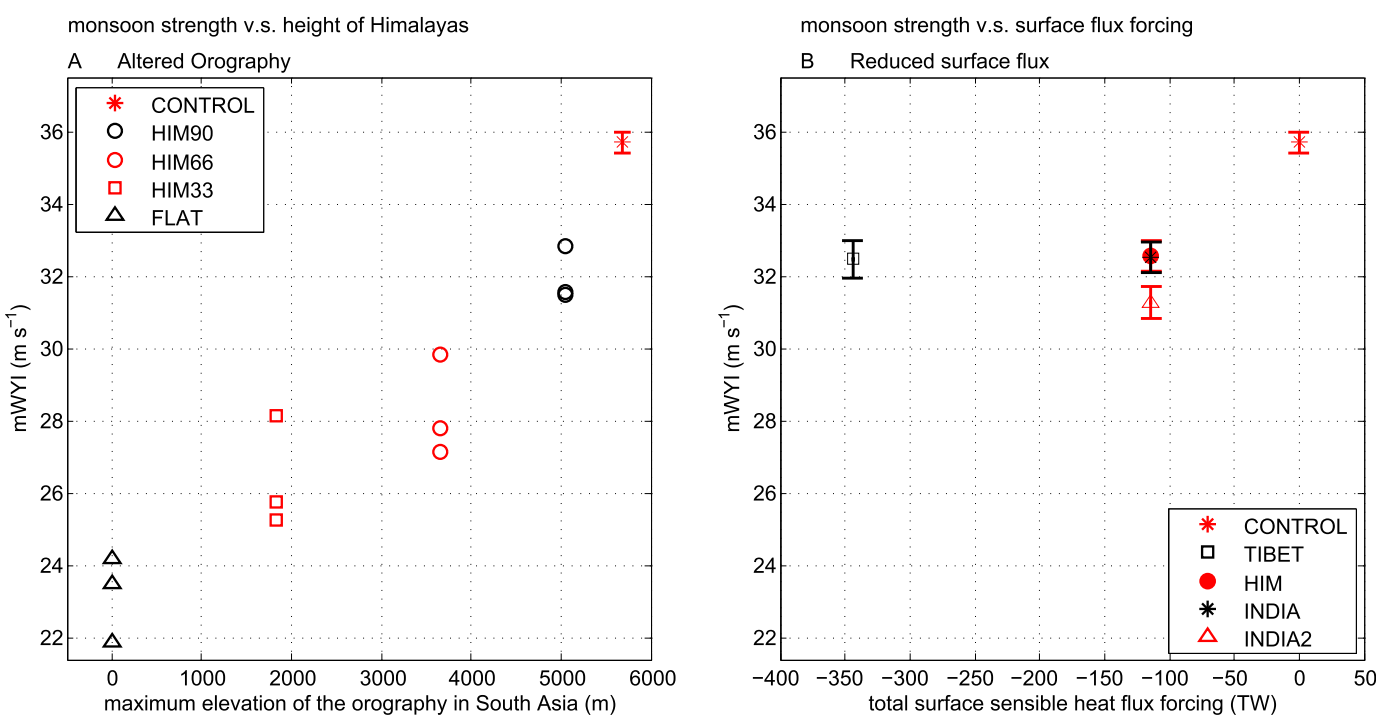

FIG. 4. The monsoon strength plotted (a) against the maximum elevation of the orography in South Asia in the experiments with altered orography and (b) against total surface sensible heat flux forcing in the experiment with sensible heat sink. The averaged mWYI of 10 ensemble members is shown with error bars for CONTROL, TIBET, HIM, INDIA, and INDIA2; the data from individual simulations is plotted for HIM90, HIM66, HIM33, and FLAT, because there are only three ensemble members for each of these experiments.

drops by more than $70 \%$ compared to the CONTROL, and the Somali jet decreases by around $4 \mathrm{~m} \mathrm{~s}^{-1}$ from $12.3 \mathrm{~m} \mathrm{~s}^{-1}$ in the CONTROL. Also, the free-tropospheric temperature peak south of the Himalayas decreases in amplitude and shifts equatorward, and the $\theta_{\mathrm{eb}}$ peak drops by around $2.5 \mathrm{~K}$ and moves southward to the Bay of Bengal (Fig. 2d). The fine resolution of this model allows a more careful look at how the monsoon strength changes when topography is modified. Results from the HIM90 experiment show that the mWYI slightly decreases, by less than $4 \mathrm{~m} \mathrm{~s}^{-1}$, compared to the CONTROL experiment. Then the monsoon circulation gradually weakens as the peaks of the Himalayas further decrease to $66 \%$ and $33 \%$ of their height in CONTROL (Fig. 4a). These experiments confirm the conclusion by Boos and Kuang (2010) that the presence of the Tibetan Plateau is not required for the existence of a strong monsoon and that the monsoon weakens as the elevation of the Himalayas decreases. The decrease of the monsoon strength is approximately linear with the decrease in the maximum elevation of the insulation with no threshold behavior observed. TIBET, HIM, INDIA, and INDIA2 are then conducted with realistic topography but reduced surface sensible heat fluxes. Because the internal variability of the mWYI grows in this group of experiments, the number of integrations for each experiment is increased to 10 to improve the signal-to-noise ratio. There is a clear dependence of the mWYI on the surface heat flux forcing whether the forcing is over elevated terrain or not. A sensible heat sink of $150 \mathrm{~W} \mathrm{~m}^{-2}$ over INDIA2 decreases the mWYI by around $4.5 \mathrm{~m} \mathrm{~s}^{-1}$, while the $\mathrm{mWYI}$ goes down by around $3 \mathrm{~m} \mathrm{~s}^{-1}$ when sensible heat sinks with the same magnitude per unit area are implemented over TIBET, HIM, and INDIA (Fig. 4b). Given the areal extent with reduced surface heat fluxes in different experiments, the monsoon is most sensitive to the forcing in INDIA2 (the nonelevated region in the location of the $\theta_{\mathrm{eb}}$ maximum) and least sensitive to that in TIBET, which is more extensive than HIM, INDIA, and INDIA2.

Figure 2 shows the spatial distribution of the $\theta_{\mathrm{eb}}$ in the experiments with orographic and surface heat flux forcing, as it was suggested that the $\theta_{\mathrm{eb}}$ maximum in north India is closely associated with the monsoon strength. It should be noted that, though the surface heat fluxes do change when the orography is reduced, the surface heat fluxes anomaly in the experiments with altered orography is very small compared to that from the experiments with reduced surface sensible heat flux. As a result, the $\theta_{e}$ anomalies in HIM90, HIM66, HIM33, and FLAT can mainly be considered as results from increased mixing between the high $\theta_{e}$ air south of the Himalayas and the dry air north of the topographic barrier. In the experiments with altered orography, the dry air from the north penetrates into north India. As the maximum height of the Himalayas is reduced, the $\theta_{\mathrm{eb}}$ over the Tibetan Plateau and north India decreases gradually and the regions with the highest $\theta_{\mathrm{eb}}$ shift southward (Figs. 2a-d). For the first group of experiments with reduced surface sensible heat fluxes (Figs. 2e-h), 

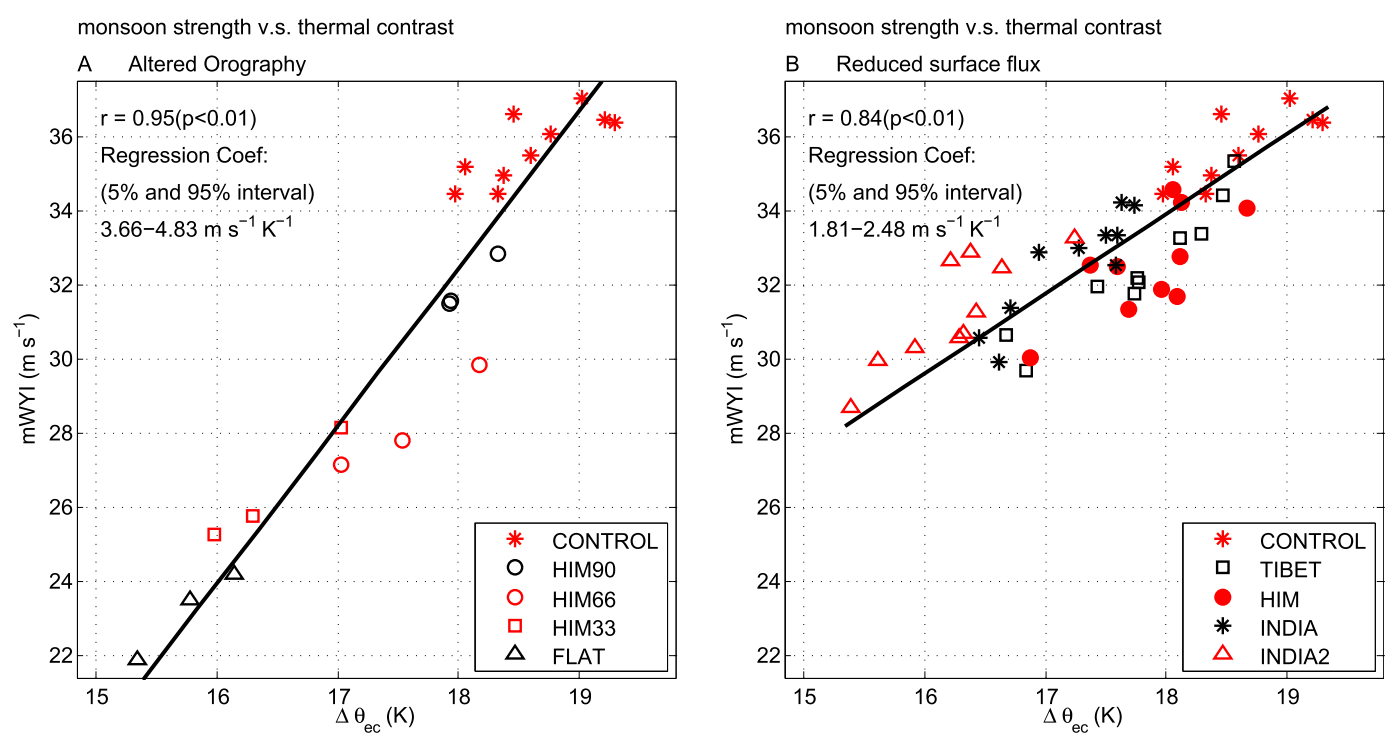

FIG. 5. The monsoon strength (indicated by mWYI) regressed against $\Delta \theta_{\mathrm{ec}}$ (i.e., the difference between the maximum $\theta_{\mathrm{eb}}$ over South Asia and the average free-tropospheric $\theta_{e}^{*}$ over the equatorial Indian Ocean) in the experiments with (a) altered orography and (b) reduced surface sensible heat fluxes. Each marker stands for an individual ensemble member, and the black line denotes the regression line.

significant negative $\theta_{\mathrm{eb}}$ anomalies can be seen in the regions where the sensible heat sink is implemented (denoted by the thick black contours), and the regions with the highest $\theta_{\mathrm{eb}}$ vary accordingly. The mWYI is most sensitive to the surface forcing in INDIA2 because the corresponding $\theta_{\mathrm{eb}}$ perturbation is coincident with the region with maximum $\theta_{\mathrm{eb}}$ in the CONTROL.

Figure 5 provides more insight into the thermal controls of the system. Since the strength of the monsoon is determined by horizontal thermal contrasts, the mWYI is plotted against an index, referred to as $\Delta \theta_{\mathrm{ec}}$, representing the thermal contrast between South Asia and the equatorial Indian Ocean. We define $\Delta \theta_{\mathrm{ec}}$ as the difference between a measure of the maximum $\theta_{\mathrm{eb}}$ over South Asia and the average saturated equivalent potential temperature $\left(\theta_{e}^{*}\right)$ in the free troposphere over the equatorial Indian Ocean. In practice, regions covering $3.7 \times 10^{6} \mathrm{~km}^{2}$ of the highest $\theta_{\mathrm{eb}}$ within $50^{\circ}-100^{\circ} \mathrm{E}, 15^{\circ}-30^{\circ} \mathrm{N}$ (the white box in Fig. 1f) are first identified for each experiment, and the maximum $\theta_{\mathrm{eb}}$ is then calculated as the average over these regions (indicated by the thick white contours in Figs. 2 and 6a). The $\theta_{e}^{*}$ is averaged horizontally over $50^{\circ}-100^{\circ} \mathrm{E}, 5^{\circ} \mathrm{S}-5^{\circ} \mathrm{N}$ (the black box in Fig. 1f) and vertically from 175 to $450 \mathrm{hPa}$. As expected, the mWYI is highly correlated with $\Delta \theta_{\mathrm{ec}}$ for both the experiments with altered orography and reduced surface heat fluxes, with the correlation coefficient of 0.95 and 0.84 , respectively (both significant at $99 \%$ confidence level). Although $\Delta \theta_{\mathrm{ec}}$ was defined in this particular way to give a measure of thermal contrast that is related to the vertical shear through thermal wind balance, the variability of the averaged free-tropospheric $\theta_{e}^{*}$ over the equatorial Indian Ocean is quite small among different experiments. The maximum $\theta_{\mathrm{eb}}$ averaged over the northern region thus dominates the variability of the thermal contrast, so the maximum $\theta_{\mathrm{eb}}$ alone also has high correlation with the mWYI.

The regression coefficients are estimated assuming the error variance on each axis is proportional to the variance of the corresponding variable. For the experiments with altered orography, the slope is $4.25 \mathrm{~m} \mathrm{~s}^{-1} \mathrm{~K}^{-1}$, with the $95 \%$ confidence interval spanning $3.66-4.83 \mathrm{~m} \mathrm{~s}^{-1} \mathrm{~K}^{-1}$. In contrast, for the experiments with reduced surface heat fluxes, the estimated slope is $2.15 \mathrm{~m} \mathrm{~s}^{-1} \mathrm{~K}^{-1}$ with a $95 \%$ confidence interval of $1.81-2.48 \mathrm{~m} \mathrm{~s}^{-1} \mathrm{~K}^{-1}$. The difference in the regression coefficients is discussed in the next few paragraphs.

Recall that, from Fig. 2, the pattern of the $\theta_{\mathrm{eb}}$ in response to orographic forcing differs from the structure of the $\theta_{\mathrm{eb}}$ in the experiments with reduced surface heat fluxes, and these differences could contribute to the difference in the regression coefficients between the two groups of experiments seen in Fig. 5. To clarify this issue, a second group of experiments with reduced surface sensible heat fluxes is conducted, in which the pattern of the surface flux forcing mimics the pattern of the $\theta_{\mathrm{eb}}$ difference between the FLAT and CONTROL experiments. Taking the THERM1 experiment as an example, Fig. 6a shows that the second group of experiments with reduced surface heat fluxes yields a similar structure of 
A
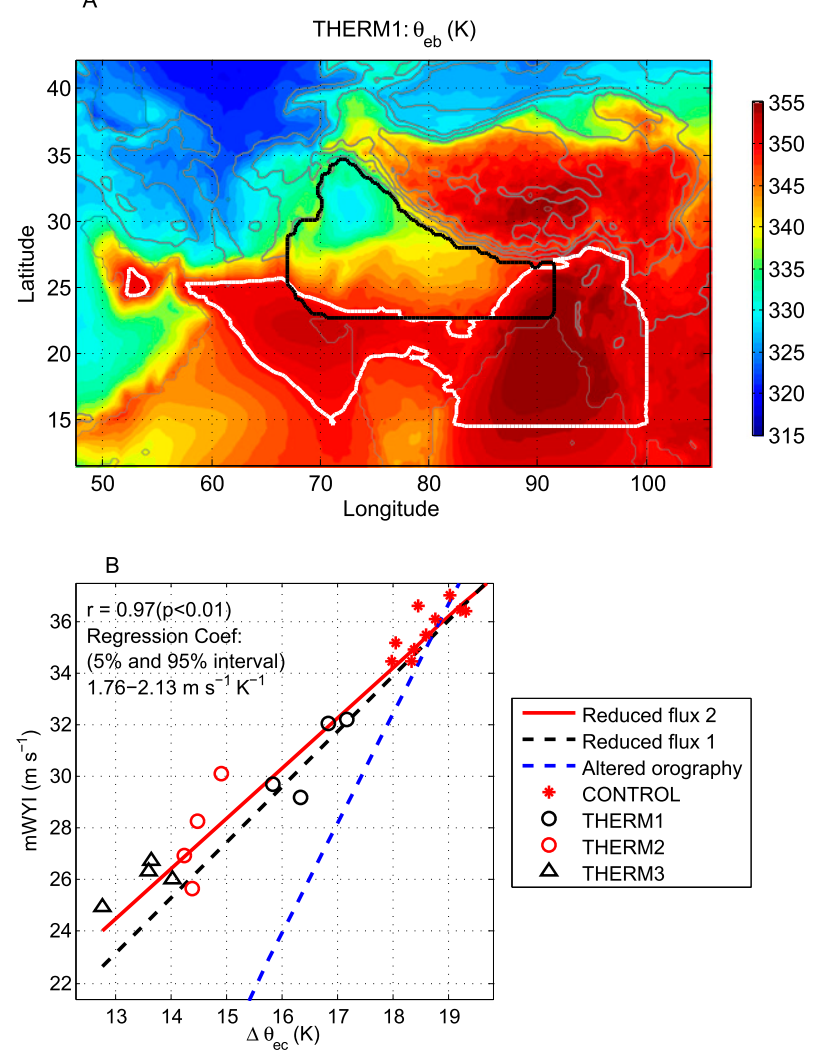

FIG. 6. (a) As in Fig. 2, but for the THERM1 experiment. (b) As in Fig. 5, but for the second group of experiments with reduced surface heat fluxes. Each marker stands for an individual integration from CONTROL, THERM1, THERM2, and THERM3, and the red solid line denotes the regression line for these simulations. As reference, the black dashed line is the same as the regression line in Fig. 5b for the first group of experiments with reduced sensible heat fluxes and the blue dashed line is the same as the regression line in Fig. 5a for the experiments with altered orography.

$\theta_{\mathrm{eb}}$ as in the FLAT experiment (Fig. 2d), with the exception of the plateau region in which no heat flux anomalies were prescribed. The indices for monsoon strength and thermal contrast (i.e., mWYI and $\Delta \theta_{\mathrm{ec}}$ ) from the second group of experiments with reduced surface heat fluxes are then regressed and presented in Fig. $6 \mathrm{~b}$. The regression line for the second group of experiments with reduced surface heat fluxes shows little difference from that for the first group. The difference in the regression coefficients between the experiments with altered orography and reduced surface heat fluxes is thus robust, and this finding motivates further examination of why altered orography produces a larger change in monsoon strength for a given perturbation in thermal contrast as measured by $\Delta \theta_{\mathrm{ec}}$.

Because the perturbation to the saturation equivalent potential temperature $\left(\theta_{e}^{*}\right)$ is much smaller than the mean value of $\theta_{e}^{*}$, the mWYI is approximately proportional to the free-tropospheric meridional $\theta_{e}^{*}$ gradient according to the thermal wind relationship. In Figs. 7a,b the mWYI is regressed against freetropospheric $\theta_{e}^{*}$ difference between South Asia and the equatorial Indian Ocean, with $\theta_{e}^{*}$ in South Asia averaged over the regions covering $3.7 \times 10^{6} \mathrm{~km}^{2}$ of the highest $\theta_{\mathrm{eb}}$ as the thick white contours in Fig. 2 indicate. The very high correlations seen in Figs. 7a,b, as expected, confirm the accuracy of this approximate thermal wind relationship. The regression coefficients are indistinguishable between the experiments with altered orography and those with reduced surface heat fluxes. Thus, the difference in the slopes between Figs. $5 \mathrm{a}$ and $5 \mathrm{~b}$ has to come from the coupling between the $\theta_{\mathrm{eb}}$ and free-tropospheric $\theta_{e}^{*}$. Without altering the orography, the values of the $\theta_{\mathrm{eb}}$ anomalies are roughly the same as those of the $\theta_{e}^{*}$ anomalies (Fig. 7d), which suggests that $\theta_{e}^{*}$ is closely coupled to $\theta_{\mathrm{eb}}$ as in strict convective quasi equilibrium. However, in the experiments with altered orography, the regressed line in Fig. $7 \mathrm{c}$ deviates from the identity line, and we suggest that this is because dry air from the north makes the entire troposphere less moist in the region of the $\theta_{\mathrm{eb}}$ maximum. The effect of the reduced Himalayas on the humidity is clearly seen in Figs. 7e,f, where the anomalous relative humidity between 400 and $700 \mathrm{hPa}$ is regressed against the $\theta_{\mathrm{eb}}$ anomalies: the relative humidity drops by $0.026 \mathrm{~K}^{-1}$ in response to surface fluxes forcing (Fig. 7f), while it drops by $0.040 \mathrm{~K}^{-1}$ in response to altered orography (Fig. 7e). Figure 8 provides cross sections of relative humidity averaged between $70^{\circ}$ and $95^{\circ} \mathrm{E}$ in relative distance to the highest elevation at that longitude. The orography creates a sharp gradient of relative humidity across the high mountains in the CONTROL (Fig. 8a). As the elevated orography is reduced, the troposphere becomes drier south of the Himalayas compared to the CONTROL (Figs. 8b-e). In contrast, in the experiments with reduced surface sensible heat fluxes, there are no significant changes in relative humidity in the free troposphere (Figs. 8f-i).

With a drier free troposphere, convective updrafts experience more severe loss of buoyancy from entrainment and require a more unstable stratification to balance the same large-scale forcing that generates convective instability. The realized convective quasi equilibrium thus deviates from a strict quasi equilibrium, in which $\theta_{e}^{*}$ anomalies are roughly equal to $\theta_{\mathrm{eb}}$ anomalies (e.g., Emanuel et al. 1994). As a result, the free-tropospheric $\theta_{e}^{*}$ over the northern region decreases more than $\theta_{\mathrm{eb}}$ in the altered orography runs, leading to a greater reduction in monsoon strength for a given decrease in $\theta_{\mathrm{eb}}$. The fact that deviations from strict quasi equilibrium can be important to the strength of the monsoon indicates the existence of complexity beyond that assumed in 
monsoon strength v.s. free trpospheric $\theta_{e}^{*}$ contrast

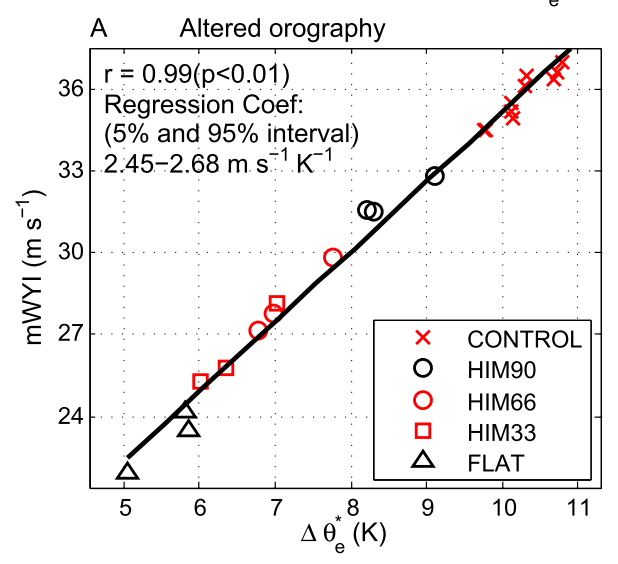

free tropospheric $\theta_{\mathrm{e}}^{*}$ anomaly v.s. $\theta_{\mathrm{eb}}$ anomaly

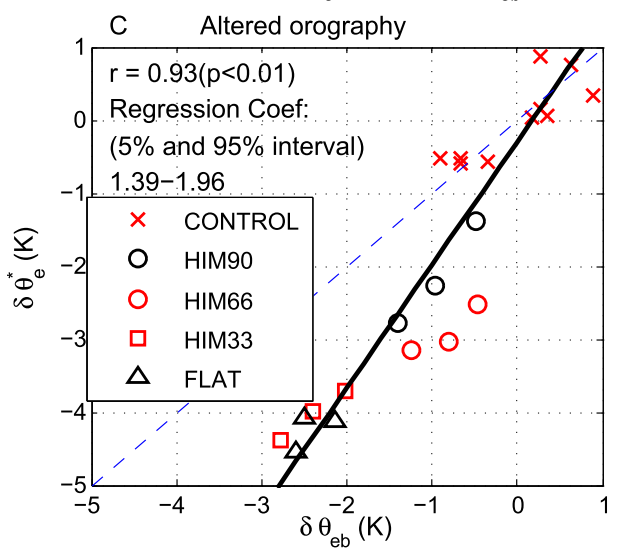

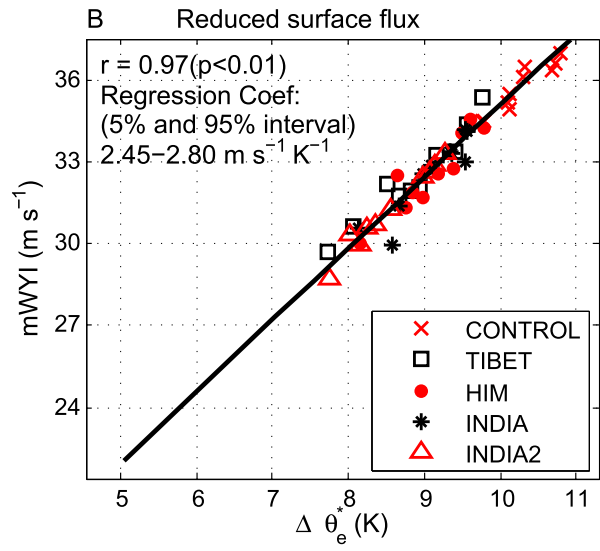

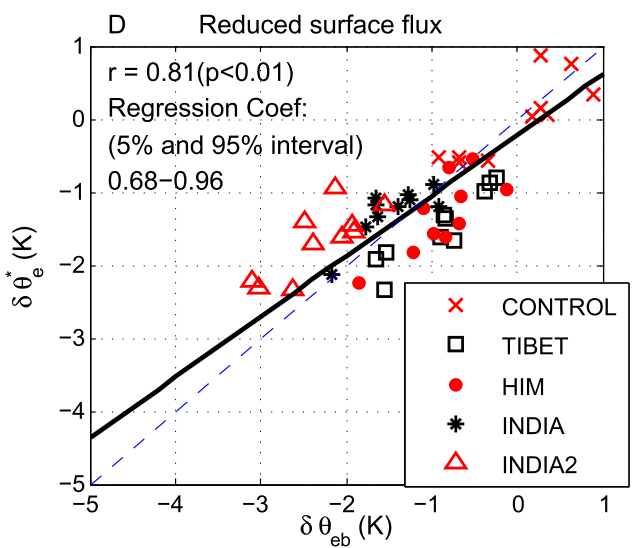

mid-tropospheric anomalous relative humidity v.s. $\theta_{\mathrm{eb}}$ anomaly
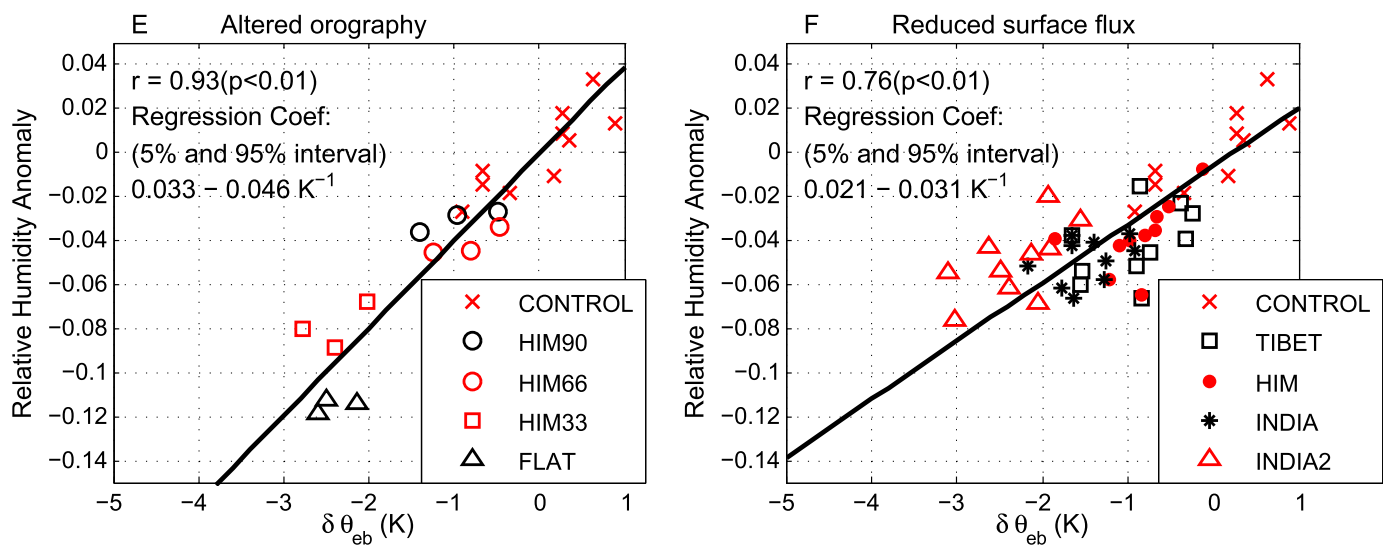

FIG. 7. (a),(b) As in Fig. 5, but the mWYI is regressed against the difference of between the free-tropospheric $\theta_{e}^{*}$ averaged over the regions covering $3.7 \times 10^{6} \mathrm{~km}^{2}$ of the highest $\theta_{\mathrm{eb}}$ and the average free-tropospheric $\theta_{e}^{*}$ over the equatorial Indian Ocean. (c)(d) As in (a),(b), but $\theta_{e}^{*}$ anomalies averaged over the regions covering $3.7 \times 10^{6} \mathrm{~km}^{2}$ of the highest $\theta_{\mathrm{eb}}$ are plotted against $\theta_{\mathrm{eb}}$ anomalies averaged in the same region. The dashed blue lines indicate the identity line. (e),(f) As in (c),(d), but the anomalous relative humidity between 400 and $700 \mathrm{hPa}$ is plotted against $\theta_{\mathrm{eb}}$ anomalies averaged over the regions covering $3.7 \times 10^{6} \mathrm{~km}^{2}$ of the highest $\theta_{\mathrm{eb}}$. 


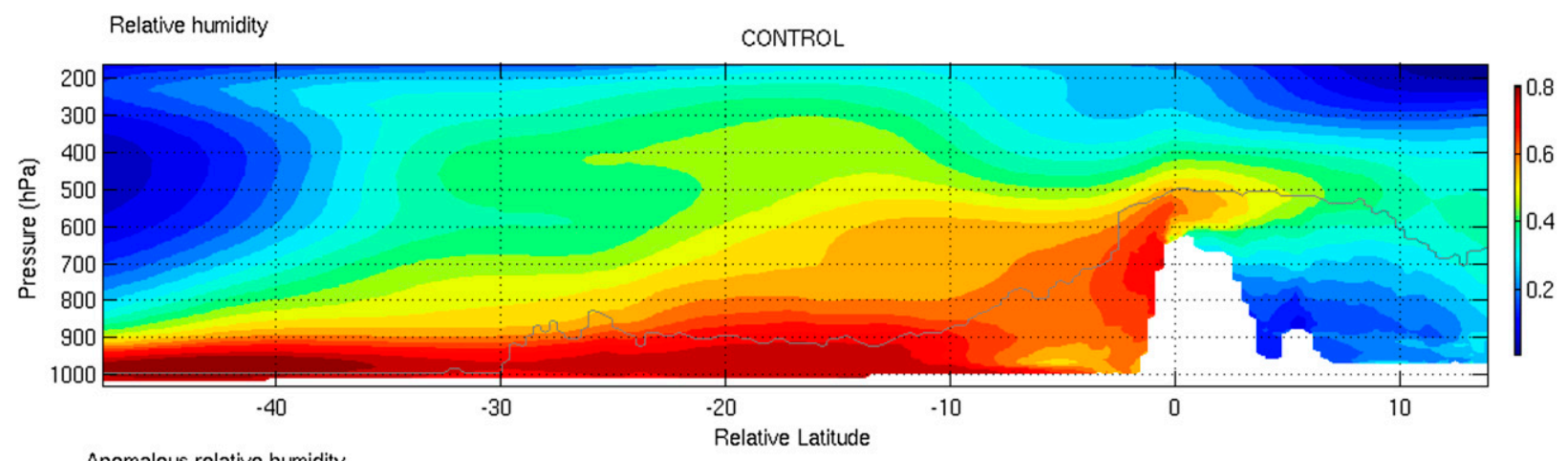

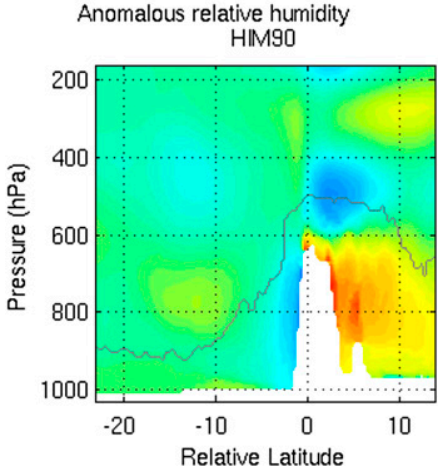

TIBET

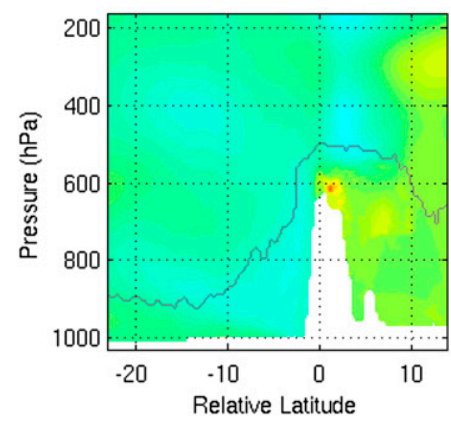

HIM66

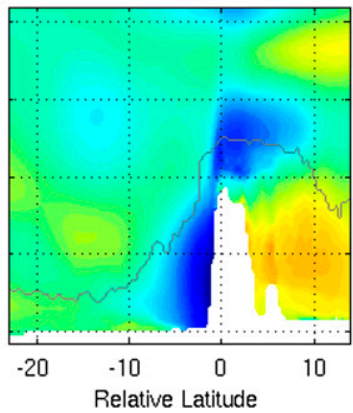

HIM

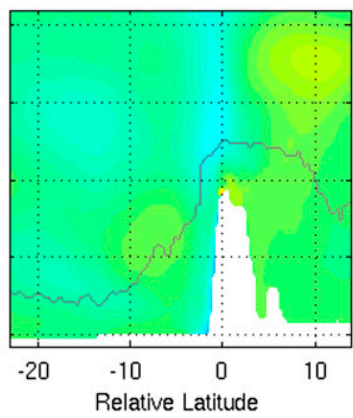

HIM33

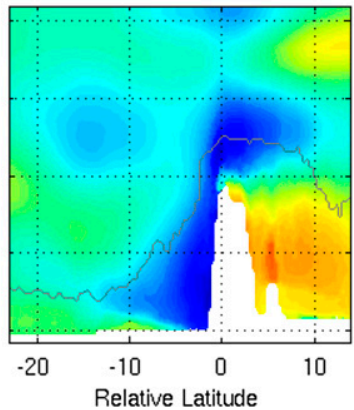

INIDA

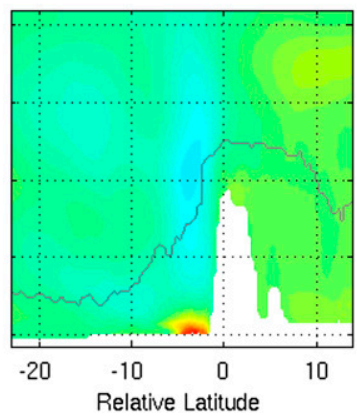

FLAT

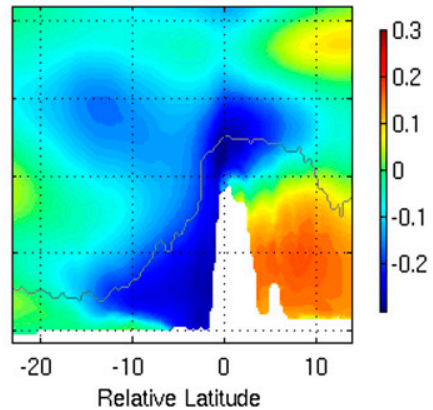

INDIA2

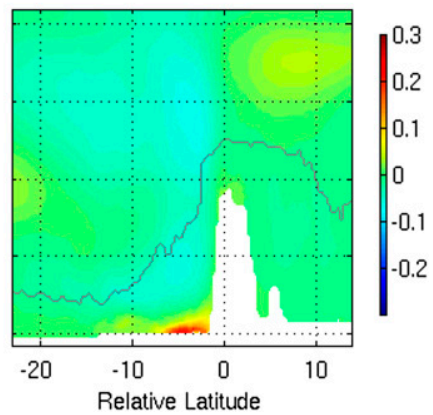

FIG. 8. (top) As in Fig. 1g, but for the relative humidity of the CONTROL. (middle),(bottom) As in (top), but for the relative humidity difference between the experiments and the CONTROL.

previous simple theories of the monsoon that are built upon strict quasi equilibrium (e.g., Emanuel 1995; Chou and Neelin 2003).

This article focuses on the main monsoon season only, but how the orography and surface heat fluxes affect the monsoon before and after the mature phase is also of scientific interest. Some previous studies suggested that latent and sensible heat fluxes over the elevated surface are significant to the timing of monsoon onset (e.g., Wu and Zhang 1998). On the other hand, Chakraborty et al. (2006) found evidence that monsoon onset requires surface moist static energy higher than a threshold value over India, and they linked the timing of monsoon onset to the west Himalayan orography as it blocks the cold extratropical air from entering northern India. More recent research has drawn attention to the importance of mechanically induced downstream convergence to the monsoon onset (e.g., Park et al. 2012). We will investigate the effects of orography and surface heat fluxes on the onset and decay phase of the monsoon with the high-resolution model for future work.

\section{Conclusions}

A high-resolution global model that resolves topography better than previous studies was used to examine effects of orography and surface heat fluxes on the South Asian summer monsoon. Experiments with altered orography and reduced surface sensible heat fluxes were conducted. As might be expected for the thermally direct monsoon circulation, we found high correlation between the strength of the monsoon, measured by the 
mWYI, and the thermal contrast between the $\theta_{\mathrm{eb}}$ maximum in South Asia and the free-tropospheric $\theta_{e}^{*}$ over the equatorial Indian Ocean. The variability in the thermal contrast in these model integrations with fixed sea surface temperature is dominated by the $\theta_{\mathrm{eb}}$ maximum, so the results can be interpreted under a convective quasi-equilibrium framework (e.g., Emanuel 1995; Prive and Plumb 2007a,b): the strength of the monsoon is closely associated with the amplitude of the $\theta_{\mathrm{eb}}$ maximum located south of the Himalayas. It is shown that, when the bulk of the Tibetan Plateau is removed, the South Asian monsoon does not change much as long as the narrow range of the Himalayas is preserved. Without the Tibetan Plateau, the monsoon weakens as the height of the Himalayas decreases, because of enhanced penetration of the low $\theta_{e}$ air from the north. Decreased surface heat fluxes in different regions can also reduce the $\theta_{\mathrm{eb}}$ maximum and weaken the monsoon, with the largest weakening occurring when the sensible heat sink is placed directly over the nonelevated regions with the highest $\theta_{\mathrm{eb}}$, consistent with the results of Boos and Kuang (2013).

However, given the same change in $\theta_{\mathrm{eb}}$, the monsoon changes more in the simulations with altered orography than in those with reduced surface heat fluxes. It is suggested that reduced orography brings dry air north of the Tibetan Plateau into the regions with the highest $\theta_{\mathrm{eb}}$ and causes this difference. In the experiments with reduced surface heat fluxes, the value of anomalous upper-tropospheric $\theta_{e}^{*}$ is approximately tied to that of the $\theta_{\mathrm{eb}}$ anomaly, as in strict convective quasi equilibrium. In contrast, when the free troposphere gets drier, convection requires a more unstable stratification, leading to a greater reduction in free-tropospheric $\theta_{e}^{*}$ than in $\theta_{\mathrm{eb}}$ and hence a greater weakening of the monsoon. These results illustrate the importance of deviations from strict quasi equilibrium in setting the strength of the monsoon, a complexity that may need to be added to existing theories of the monsoon based on strict quasi equilibrium (e.g., Emanuel 1995; Chou and Neelin 2003), and call attention to an additional mechanism through which the monsoon may respond to changes in the hydrological cycle.

Acknowledgments. This research was partially supported by NSF Grants AGS-0754332 and AGS-1062016 and a grant from Harvard's Asia center. W.R.B. acknowledges support from Office of Naval Research Award N00014-11-1-0617 and National Science Foundation Award AGS1253222. Sincere thanks go to Peter Molnar for pointing out an error in an earlier draft of the manuscript among other very constructive comments. The authors thank two anonymous reviewers for the helpful reviews and the Harvard FAS Science Division Research Computing Group for computing support. Z.K. thanks Peter Clark for discussions.

\section{REFERENCES}

Abe, M., A. Kitoh, and T. Yasunari, 2003: An evolution of the Asian summer monsoon associated with mountain uplift-Simulation with the MRI atmosphere-ocean coupled GCM. J. Meteor. Soc. Japan, 81, 909-933, doi:10.2151/ jmsj.81.909.

An, Z., J. E. Kutzbach, W. L. Prell, and S. C. Porter, 2001: Evolution of Asian monsoons and phased uplift of the HimalayaTibetan Plateau since Late Miocene times. Nature, 411, 62-66, doi:10.1038/35075035.

Boos, W., and K. A. Emanuel, 2009: Annual intensification of the Somali jet in a quasi-equilibrium framework: Observational composites. Quart. J. Roy. Meteor. Soc., 135, 319-335, doi:10.1002/qj.388.

— monsoon by orographic insulation versus plateau heating. Nature, 463, 218-223, doi:10.1038/nature08707.

— model mean boreal summer monsoon. J. Climate, 26, 2279 2287, doi:10.1175/JCLI-D-12-00493.1.

_ , and Z. Kuang, 2013: Sensitivity of the South Asian monsoon to elevated and non-elevated heating. Sci. Rep., 3, 1192, doi:10.1038/srep01192.

Cane, M. A., 2010: Climate: A moist model monsoon. Nature, 463, 163-164, doi:10.1038/463163a.

Chakraborty, A., R. Nanjundiah, and J. Srinivasan, 2002: Role of Asian and African orography in Indian summer monsoon. Geophys. Res. Lett., 29, 1989, doi:10.1029/2002GL015522.

,-- , and 2006: Theoretical aspects of the onset of Indian summer monsoon from perturbed orography simulations in a GCM. Ann. Geophys., 24, 2075-2089, doi:10.5194/ angeo-24-2075-2006.

Chou, C., and J. D. Neelin, 2003: Mechanisms limiting the northward extent of the northern summer monsoons over North America, Asia, and Africa. J. Climate, 16, 406-425, doi:10.1175/ 1520-0442(2003)016<0406:MLTNEO > 2.0.CO;2.

Emanuel, K. A., 1995: On thermally direct circulation in moist atmospheres. J. Atmos. Sci., 52, 1529-1534, doi:10.1175/ 1520-0469(1995)052<1529:OTDCIM>2.0.CO; 2 .

_ J. D. Neelin, and C. S. Bretherton, 1994: On large-scale circulations in convecting atmospheres. Quart. J. Roy. Meteor. Soc., 120, 1111-1143, doi:10.1002/qj.49712051902.

Gill, A. E., 1980: Some simple solutions for heat-induced tropical circulation. Quart. J. Roy. Meteor. Soc., 106, 447-462, doi:10.1002/qj.49710644905.

Hahn, D. G., and S. Manabe, 1975: The role of mountains in the South Asian monsoon circulation. J. Atmos. Sci., 32, 1515-1541, doi:10.1175/1520-0469(1975)032<1515:TROMIT>2.0.CO;2.

He, H., J. McGinnis, Z. Song, and M. Yanai, 1987: Onset of the Asian summer monsoon in 1979 and the effect of the Tibetan Plateau. Mon. Wea. Rev., 115, 1966-1995, doi:10.1175/ 1520-0493(1987)115<1966:OOTASM>2.0.CO;2.

Hurley, J. V., and W. Boos, 2013: Interannual variability of monsoon precipitation and local subcloud equivalent potential temperature. J. Climate, 26, 9507-9527, doi:10.1175/JCLI-D-12-00229.1.

Kuang, Z., P. N. Blossey, and C. S. Bretherton, 2005: A new approach for $3 \mathrm{D}$ cloud-resolving simulations of large-scale 
atmospheric circulation. Geophys. Res. Lett., 32, L02809, doi:10.1029/2004GL021024.

Lau, K. M., M. K. Kim, and K. M. Kim, 2006: Asian summer monsoon anomalies induced by aerosol direct forcing: The role of the Tibetan Plateau. Climate Dyn., 26, 855-864, doi:10.1007/s00382-006-0114-z.

Molnar, P., W. Boos, and D. S. Battisti, 2010: Orographic controls on climate and paleoclimate of Asia: Thermal and mechanical roles for the Tibetan Plateau. Annu. Rev. Earth Planet. Sci., 38, 77-102, doi:10.1146/annurev-earth-040809-152456.

Park, H.-S., J. C. H. Chiang, and S. Bordoni, 2012: The mechanical impact of the Tibetan Plateau on the seasonal evolution of the South Asian monsoon. J. Climate, 25, 2394-2407, doi:10.1175/ JCLI-D-11-00281.1.

Prell, W. L., and E. Kutzbach, 1992: Sensitivity of the Indian monsoon to forcing parameters and implications for its evolution. Nature, 360, 647-652, doi:10.1038/ $360647 \mathrm{a} 0$.

Prive, N. C., and R. A. Plumb, 2007a: Monsoon dynamics with interactive forcing. Part I: Axisymmetric studies. J. Atmos. Sci., 64, 1417-1430, doi:10.1175/JAS3916.1.

_, and —_, 2007b: Monsoon dynamics with interactive forcing. Part II: Impact of eddies and asymmetric geometries. J. Atmos. Sci., 64, 1431-1442, doi:10.1175/ JAS3917.1.
Wang, B., R. Wu, and K. M. Lau, 2001: Interannual variability of the Asian summer monsoon: Contrasts between the Indian and the western North Pacific-East Asian monsoons. J. Climate, 14, 4073-4090, doi:10.1175/1520-0442(2001)014<4073: IVOTAS $>2.0 . \mathrm{CO} ; 2$.

Webster, P. J., and S. Yang, 1992: Monsoon and ENSO: Selectively interactive systems. Quart. J. Roy. Meteor. Soc., 118, 877-926, doi:10.1002/qj.49711850705.

Wu, G., and Y. Zhang, 1998: Tibetan Plateau forcing and the timing of the monsoon onset over South Asia and the South China Sea. Mon. Wea. Rev., 126, 913-927, doi:10.1175/ 1520-0493(1998)126<0913:TPFATT>2.0.CO;2.

—, Y. Liu, B. He, Q. Bao, A. Duan, and F. Jin, 2012: Thermal controls on the Asian summer monsoon. Sci. Rep., 2, 404, doi:10.1038/srep00404.

Yanai, M., C. Li, and Z. Song, 1992: Seasonal heating of the Tibetan Plateau and its effects on the evolution of the Asian summer monsoon. J. Meteor. Soc. Japan, 70, 189-211.

Yasunari, T., K. Saito, and K. Takata, 2006: Relative roles of largescale orography and land surface processes in the global hydroclimate. Part I: Impacts on monsoon systems and the tropics. J. Hydrometeor., 7, 626-641, doi:10.1175/JHM515.1.

Yeh, T. C., S. W. Lo, and P. C. Shu, 1957: The wind structure and heat balance in the lower troposphere over Tibetan Plateau and its surroundings. Acta Meteor. Sin., 28, 108-121. 